\title{
Gender Power and Family Decision in an Extended Solowian Economic Growth Model
}

\author{
Prof. Wei-Bin Zhang \\ Ritsumeikan Asia Pacific University, Japan \\ wbz1@apu.ac.jp
}

\begin{abstract}
The purpose of this paper is to deal with dynamic interdependence between economic growth and family-based behavior. The decision unit on consumption and saving is the family which is composed of the husband and the wife. The model endogenously determines national growth, family goods, family wealth, and gender-differentiated consumption and labor supply with fixed distribution of power between the husband and the wife. The model is based on synthesizing a few approaches in economics. The growth mechanism and economic structure are based on a generalized Solowian growth model. The household behavior is based on Zhang's concept of disposable income and utility. The power distribution is referred to the collective approach by Basu (2006). We first develop the model and study dynamic behavior of the model. We conduct comparative dynamic analyses to demonstrate how economic growth interacts with family behavior by allowing exogenous changes in gender power distribution, gender-based preferences and human capital, and national technological changes.
\end{abstract}

Keywords. gender power, family decision, economic growth, Solow model

\section{Introduction}

In his classical paper Social Indifference Curves, Paul Samuelson (1956) points out the situation in microeconomics: "Who after all is the consumer in the theory of consumer's (not consumers') behavior? Is he a bachelor? A spinster? Or is he a "spending unit" as defined by statistical pollsters and recorders of budgetary spending? In most of the cultures actually studied by modern economists, the fundamental unit on the demand side is clearly the "family" and this consists of a single individual in a fraction of cases." In the standard unitary model, all the decisions of the household are due to the same preference or decided by a single spouse (e.g., Becker, 1981). In last few decades economists have made great efforts in analyzing decisions and behavior of family of heterogeneous members, applying different analytical tools (e.g., Bergstrom, 1996; Rosenzweig and Stark, 1997; Campbell and Ludvigson, 2001; Chen and Woolley, 2001; Vendrik, 2003; Zhang, 2016; and Chiappori, 2018). Economists have modelled issues related to marriage, divorce, intrahousehold distribution of consumption, wealth and work, intergeneration and interhousehold links, caring and cost of children, fertility, mortality, number of children, health, and many other issues. Although there are great progresses in family economics, it is argued that there are only a few macroeconomic growth models with endogenous wealth based on family economics. The purpose of this study is to make a contribution to the literature of macroeconomics based neoclassical growth theory and 
family economics by integrating some important ideas in neoclassical growth theory and family economics.

In his AEA Presidential Address, Becker (1988) emphasized the significance of building macroeconomic theory based on family economics. Macroeconomic theories without taking account of family decisions ignore some basic forces of economic growth. There are many studies on family and macroeconomics (for recent literature, e.g., Blundell, et al., 2016; Doepke and Tertilt, 2016). This study models economic mechanism of growth and economic structure on the basis of neoclassical growth theory (e.g., Solow, 1956; Uzawa, 1961; Burmeister and Dobell 1970; Azariadis, 1993; Jensen and Larsen, 2005; and Ben-David and Loewy, 2003). As pointed out by Doepke and Tertilt (2016: 1791), "typical macroeconomic models ignore the family and instead build on representative agent modelling that abstracts from the presence of multiple family members, who may have conflicting interests, who might make separate decisions, and may split up and form new households." A main deviation of this study from the mainstream approaches in family economics is application of concept of disposable income and utility function proposed by Zhang (1993, 2005). Family decisions are based on the collective approach adopted by Basu (2006). In contemporary approach to household behavior, the household decisions are due to cooperation, and competition, caring. Basu develops a model in which a household's decisions are dependent on the power balance between the husband and the wife. Both husband and woman have their own utility functions. The household decisions are modelled by maximizing the family utility function which is "weighted" average of the husband and wife's utility functions. The weight measures the balance of the household. It should be noted that Zhang $(2012,2016)$ deals with genderdifferentiated neoclassical growth theories. This study is an extension of Zhang's previous models in that the family decision is modelled with the collective approach. The paper is organized as follows. Section 2 builds a neoclassical one-sector growth model with the collective approach to family decision. Section 3 examines dynamic properties of the economy and shows the existence of a unique stable equilibrium. Section 4 carries out comparative dynamic analysis with regards to changes in the power balance, gender-differentiated preferences and human capital, and the total factor productivity. Section 5 makes concluding remarks.

\section{The growth model with the collective approach to family decisions}

This section develops the neoclassical growth model with the collective approach to family decisions. Most aspects of the model with regards to production and market structures are based on the Solow one-sector growth model. There are two homogenous populations, male population and female population, with the same number $\bar{N}$. Man and woman form a family. Markets are characterized by perfect competition. Let subscript $j=1$ and $j=2$ stand for man and woman, respectively. As in the Solow model, one commodity is produced and is used for consumption and saving. Capital depreciation rate is fixed at $\delta_{k}$. All assets are owned by the family. Capital and labor Inputs are fully employed. All prices are measured in terms of commodity whose price is unity. Spouse $j^{\prime}$ s wage rate $w_{j}(t)$ and rate of interest $r(t)$ are given in free markets. The economy has total capital stock $K(t)$. Let $h_{j}$ represent gender $j$ 's human capital fixed (in this study). Fair competition in labor market implies $w_{j}(t)=h_{j} w(t)$, where $w(t)$ is the wage rate. The national labor supply $N(t)$ is thus given by:

$$
N(t)=h_{1} T_{1}(t) \bar{N}+h_{2} T_{2}(t) \bar{N},
$$


where $T_{j}(t)$ is gender $j^{\prime}$ s work time.

\section{Family's current income and disposable income}

As a member of the union, the husband and wife care each other. They share and consume a family (public) goods and wealth. The husband and the wife have their own (private) consumption. They have their own utility function. But their decisions are made a unit. They maximize the family utility function subject to the family budget. Each spouse's utility is dependent not only his/her own consumption, but also the partner's consumption. We use $\bar{k}(t)$ to stand for the family wealth. The family has the following current income:

$$
y(t)=r(t) \bar{k}(t)+T_{1}(t) w_{1}(t)+T_{2}(t) w_{2}(t),
$$

where $r(t) \bar{k}(t)$ is the interest income. The family disposable income is the sum of the current income and value of wealth:

$$
\hat{y}(t)=y(t)+\bar{k}(t)=R(t) \bar{k}(t)+T_{1}(t) w_{1}(t)+T_{2}(t) w_{2}(t)
$$

where $R(t) \equiv 1+r(t)$. Each member of the family has equal constant available time $T_{0}$ for work $T_{j}(t)$ and for leisure $\bar{T}_{j}(t)$. The time constraints imply:

$$
T_{j}(t)+\bar{T}_{j}(t)=T_{0}
$$

Insert (4) in (3)

$$
\hat{y}(t)=\bar{y}(t)-\bar{T}_{1}(t) w_{1}(t)-\bar{T}_{2}(t) w_{2}(t),
$$

where

$$
\bar{y}(t) \equiv R(t) \bar{k}(t)+T_{0} w_{1}(t)+T_{0} w_{2}(t)
$$

We call $\bar{y}(t)$ the family's potential disposable income as it is the disposable income when both the husband and the wife work full time without any leisure.

\section{Family utility function}

Family utility is based on the collective approach adopted by Basu (2006). The family's decision is dependent on the power balance between the husband and the wife. The household decisions are modelled by maximizing the family utility function which is "weighted" average of the husband and wife's utility functions. Gender $j$ 's well-being is given by an egocentric utility function $U_{j}(t)$ which is dependent on gender $j$ 's private consumption $c_{j}(t)$, the family saving $s(t)$, family good $\bar{c}(t)$, and the spouse's consumption $c_{i}(t)$ as follows:

$$
U_{j}(t)=\bar{T}_{j}^{\sigma_{j 0}}(t) c_{j}^{\xi_{j 0}}(t) \bar{c}^{\gamma_{j 0}}(t) s^{\lambda_{j 0}}(t) c_{i}^{\epsilon_{0 j}}(t), \xi_{j 0}, \gamma_{j 0}, \lambda_{j 0}, \epsilon_{0 j}>0, j \neq i,(6)
$$

where $\sigma_{j 0}$ is gender j's propensity to stay at home, $\xi_{j 0}$ is gender j's propensity to consume private goods, $\gamma_{j 0}$ is propensity to consume family goods, $\lambda_{0 j}$ is propensity to make family- 
saving, and $\epsilon_{0 j}$ is the propensity to care about the spouse's private consumption. Household good is characterized by being non-rival. Husband and wife's egocentric utility functions are different. It should be noted that when each spouse cares the other's utility rather than consumption levels, the preference is termed caring preferences (Becker, 1988; see also Bourguignon and Chiappori, 1992). Like Basu (2006), we use $\theta$ and $1-\theta$ to measure man's power and woman's power respectively. As $\theta$ rises, the power of the husband increases. For simplicity, this study assumes $\theta$ fixed. We will allow the power parameter to exogenously vary in comparative dynamics analysis late on. It should be noted that it is conceptually and analytically not difficult to treat power parameters as functions of wealth, wage ratio and other variables. The family utility is formed as follows:

$U(t)=U_{1}^{\theta}(t) U_{2}^{1-\theta}(t)$

From (6) and (3), we have

$U(t)=\bar{T}_{1}^{\theta \sigma_{10}}(t) \bar{T}_{2}^{(1-\theta) \sigma_{20}}(t) c_{1}^{\bar{\xi}_{01}}(t) c_{2}^{\bar{\xi}_{02}}(t) \bar{c}^{\gamma_{0}}(t) s^{\lambda_{0}}(t)$

where

$\lambda_{0} \equiv \theta \lambda_{10}+(1-\theta) \lambda_{20}, \gamma_{0} \equiv \theta \gamma_{10}+(1-\theta) \gamma_{20}$
$\bar{\xi}_{01} \equiv \theta \xi_{10}+(1-\theta) \epsilon_{02}, \bar{\xi}_{02} \equiv \theta \epsilon_{01}+(1-\theta) \xi_{20}$.

Family budget and family decision

The family budget is formed as:

$$
c_{1}(t)+c_{2}(t)+\bar{c}(t)+s(t)=\hat{y}(t) .
$$

The family disposable income is distributed between the couple's private consumption, family good, and saving. Insert (5) in (9)

$$
\bar{T}_{1}(t) w_{1}(t)+\bar{T}_{2}(t) w_{2}(t)+c_{1}(t)+c_{2}(t)+\bar{c}(t)+s(t)=\bar{y}(t)
$$

The family maximizes the utility function under (10). The first-order conditions for the family's maximization are as follows:

$$
\bar{T}_{j}(t)=\frac{\sigma_{j} \bar{y}(t)}{w_{j}(t)}, \quad c_{j}(t)=\xi_{j} \bar{y}(t), \quad \bar{c}(t)=\gamma \bar{y}(t), \quad s(t)=\gamma \bar{y}(t)
$$

where

$$
\begin{gathered}
\sigma_{1} \equiv \rho \theta \sigma_{10}, \sigma_{2} \equiv(1-\theta) \rho \sigma_{20}, \xi_{1} \equiv \rho \bar{\xi}_{01}, \xi_{2} \equiv \rho \bar{\xi}_{02}, \gamma \equiv \rho \gamma_{0}, \lambda \equiv \rho \lambda_{0}, \\
\rho \equiv \frac{1}{\theta \sigma_{10}+(1-\theta) \sigma_{20}+\bar{\xi}_{01}+\bar{\xi}_{02}+\gamma_{0}+\lambda_{0}} .
\end{gathered}
$$

Wealth accumulation

According to the definition of $s(t)$, the change in family wealth is given by: 


$$
\dot{\bar{k}}(t)=s(t)-\bar{k}(t)
$$

The change in the family wealth is equal to the family's saving minus the family's dissaving.

Production sector

The production function $F(t)$ is taken on the Cobb-Douglas form:

$$
F(t)=A K^{\alpha}(t) N^{\beta}(t), \alpha, \beta>0, \alpha+\beta=1,
$$

where $A, \alpha$, and $\beta$ are positive parameters. The marginal conditions are:

$$
r(t)+\delta_{k}=\frac{\alpha F(t)}{K(t)}, w(t)=\frac{\beta F(t)}{N(t)} .
$$

Demand and supply of goods

The equilibrium condition that the output of the production sector is equal to the depreciation of capital stock and the net savings is expressed as:

$$
C(t)+S(t)-K(t)+\delta_{k} K(t)=F(t)
$$

where

$$
S(t)=s(t) \bar{N}, \quad C(t)=c_{1}(t) \bar{N}+c_{2}(t) \bar{N} .
$$

The sum of all the families' wealth is equal to national wealth

$$
K(t)=\bar{k}(t) \bar{N} .
$$

We thus built the model. The model is an extension of neoclassical growth theory and is based on some ideas in family economics. We now study behavior of the model.

\section{The movement of the economy}

This section plots the movement of the economy and shows the existence of a unique equilibrium point. We introduce a variable as:

$$
z \equiv \frac{r+\delta_{k}}{w}
$$

Lemma

The motion of $z(t)$ is given by one differential equation as follows:

$$
\dot{z}(t)=\Phi(z(t))
$$

where function $\Phi(z(t))$ is given in the Appendix. All the other variables are determined as functions of $z(t)$ as follows: $r(t)$ by $(\mathrm{A} 2) \rightarrow w(t)$ by $(\mathrm{A} 2) \rightarrow \bar{k}(t)$ with $(\mathrm{A} 7) \rightarrow K(t)=\bar{k}(t) \bar{N}$ 
$\rightarrow w_{j}(t)=h_{j} \mathrm{w}(t) \rightarrow T_{j}(t)$ by $(\mathrm{A} 4) \rightarrow \bar{T}_{j}(t)=T_{0}-T_{j}(t) \rightarrow N(t)$ by $(1) \rightarrow F(t)$ by $(13) \rightarrow$ $\bar{y}(t)$ by the definition $\rightarrow c_{j}(t), \bar{c}(t)$ and $s(t)$ by $(11) \rightarrow U_{j}(t)$ by $(6) \rightarrow U(t)$ by (7).

As the expressions are complicated, we show dynamic behavior of the system by simulation. The parameters are taken on the following values:

$$
\begin{gathered}
A=1.2, T_{0}=24, \alpha=0.35, \bar{N}=100, h_{1}=2.2, h_{2}=2, \delta_{k}=0.05, \varepsilon_{10}=0.1, \\
\varepsilon_{20}=0.1, \theta=0.45, \xi_{10}=0.2, \lambda_{10}=0.6, \gamma_{10}=0.2, \sigma_{10}=0.25, \xi_{20}=0.15, \\
\lambda_{20}=0.62, \gamma_{20}=0.15, \sigma_{20}=0.22 .
\end{gathered}
$$

The total factor productivity is 1.2 . The national population is 200 . The choice of population sizes is not important as far as our purposes of providing some insights into economic mechanisms of the system and comparative dynamic analysis. The parameter $\alpha$ in the Cobb-Douglas production is taken on 0.35. In empirical studies the value is often taken on 1/3 (for instance, Miles and Scott, 2005; Abel et al., 2007). The depreciation rate of physical capital is fixed at 0.05 . Under (17) and the initial conditions:

$$
z(0)=0.25
$$

We plot the movement of the economy as in Figure 1.
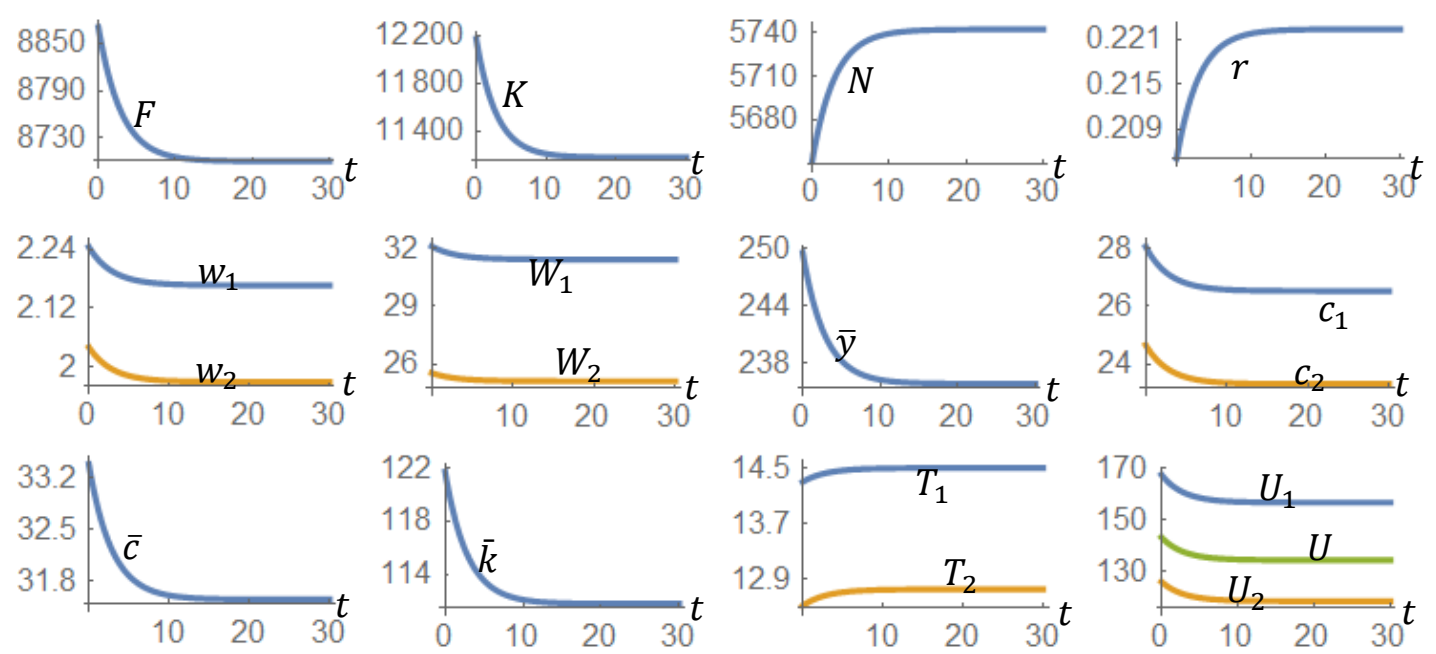

Figure 1. The Motion of the Economic System

The national output and national capital stock fall. The changes of the other variables over time are plotted in Figure 1. As oserved from Figure 1, the system tends to become stationary. Simulation identifies a unique equilibrium point as follows:

$$
\begin{gathered}
F=8699.8, K=11177.8, \quad N=5742.3, r=0.222, w_{1}=2.17, \quad w_{2}=1.97, \\
W_{1}=31.4, W_{2}=25.1, \bar{y}=235.9, c_{1}=26.5, c_{2}=23.3, \bar{c}=31.56, \\
\bar{k}=111.8, T_{1}=14.5, T_{2}=12.8, U_{1}=156.6, \quad U_{2}=118.5, \quad U=134.3 .(18)
\end{gathered}
$$

At equilibrium the husband has higher income than the wife. The husband consumes more goods than the wife. The husband makes more contribution to family goods than the wife. The wife has more wealth than the husband. The husband has higher egocentric utility than the wife; 
but the wife has higher well-being than the husband as she derives much more pleasure from him than he from her. The eigenvalue is -0.346 . The equilibrium point is stable. We can thus effectively conduct comparative dynamic analysis.

\section{Comparative statics analysis}

We illustrated the movement of the economy system and identified the existence of a unique stable equilibrium point. This section studies how the economic dynamics changes when some parameters are exogenously shifted. We introduce $\bar{\Delta} x(t)$ to stand for the change rate of variable $x(t)$ in percentage caused by an exogenous change in a parameter.

\section{The husband has less power in family decision making}

We study how the economy is changed if the husband has less power in family decision making in the following way: $\theta: 0.45 \Rightarrow 0.43$. Figure 2 provides the simulation result. As the wife has more power, her consumption of goods is increased, while the husband's consumption is reduced. The wife works less hours, while the husband works more hours. The wage rates is are increased equally. The husband brings more wage income, while the wife brings less. The labor supply rises initially but falls in the long term. The total labor supply and national output are increased. The rate of interest falls. The family's potential disposable income is enhanced. The family good falls initially but rises in the long term. The family has more wealth. The wife's utility is enhanced, while the husband's utility is decreased. The family's aggregated utility is slightly affected. The redistribution of power from the husband to the wife benefits the national economic growth, enhances the wife's utility, lowers the husband's utility, and has little impact on the family's utility.
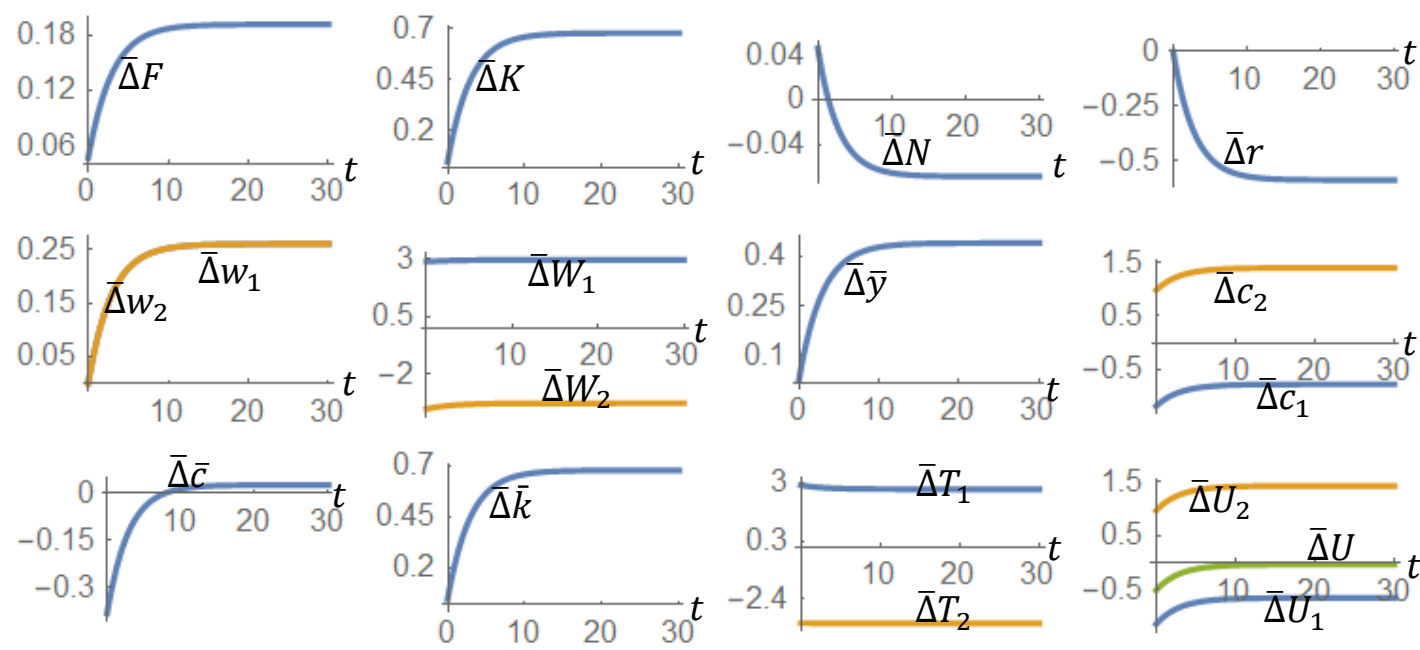

Figure 2. The Husband Has Less Power in Family Decision Making

\section{The wife's human capital is enhanced}

We study how the economy is changed if the wife's human capital is enhanced in the following way: $h_{2}: 2 \Rightarrow 2.1$. Figure 3 provides the simulation result. As the wife has higher human capital, her wage rate is enhanced. The husband's wage rate is not affected. The wife works more hours, while the husband works less hours. The husband brings less wage income, while the wife brings more. The couple's consumption levels of good are increased in the same rate. The family has more family goods and more wealth. Both the husband and the wife have 
higher utility levels, while the wife's increase rate is higher than the husband's. The economy has more capital, produces more, and has more labor force. The rate of interest is not affected.
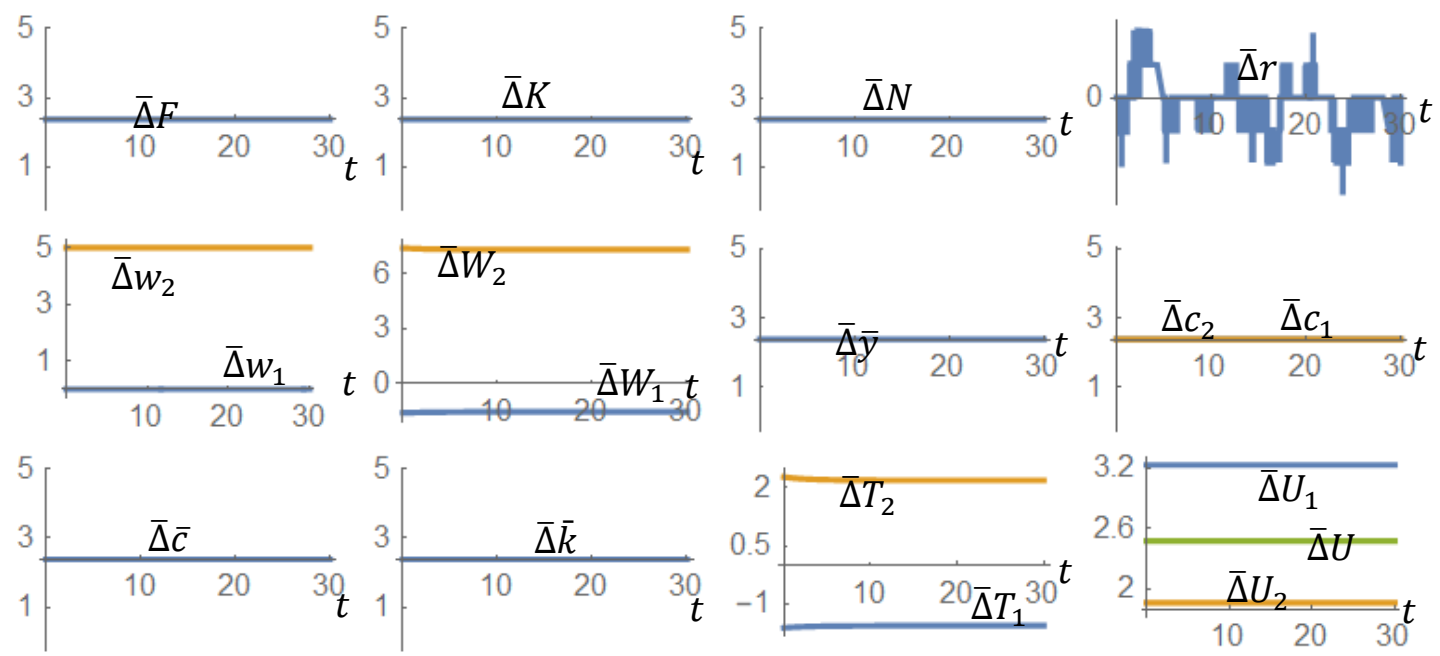

Figure 3. The Wife's Human Capital is Enhanced

\section{The wife cares more about her husband}

We study how the economy is changed if the wife cares more her husband in the following way: $\epsilon_{2}: 0.1 \Rightarrow 0.12$. Figure 4 provides the simulation result. As the wife cares more about her spouse, her consumption level of goods is reduced, while her husband's consumption level is enhanced. The couple work more hours. The wage rates are reduced. The family has more wealth initially, but less in the long term. The family good is reduced. The economy has more wealth and output initially but has less wealth and output in the long term. In the long term the husband and wife bring less wage incomes. The wife has higher utility level, but the husband has lower utility level. This implies that the wife's more caring about her husband actually reduces her husband's utility. This occurs because the wife's preference change reduces the family saving and family good supply. The net impact on the husband's utility is negative.
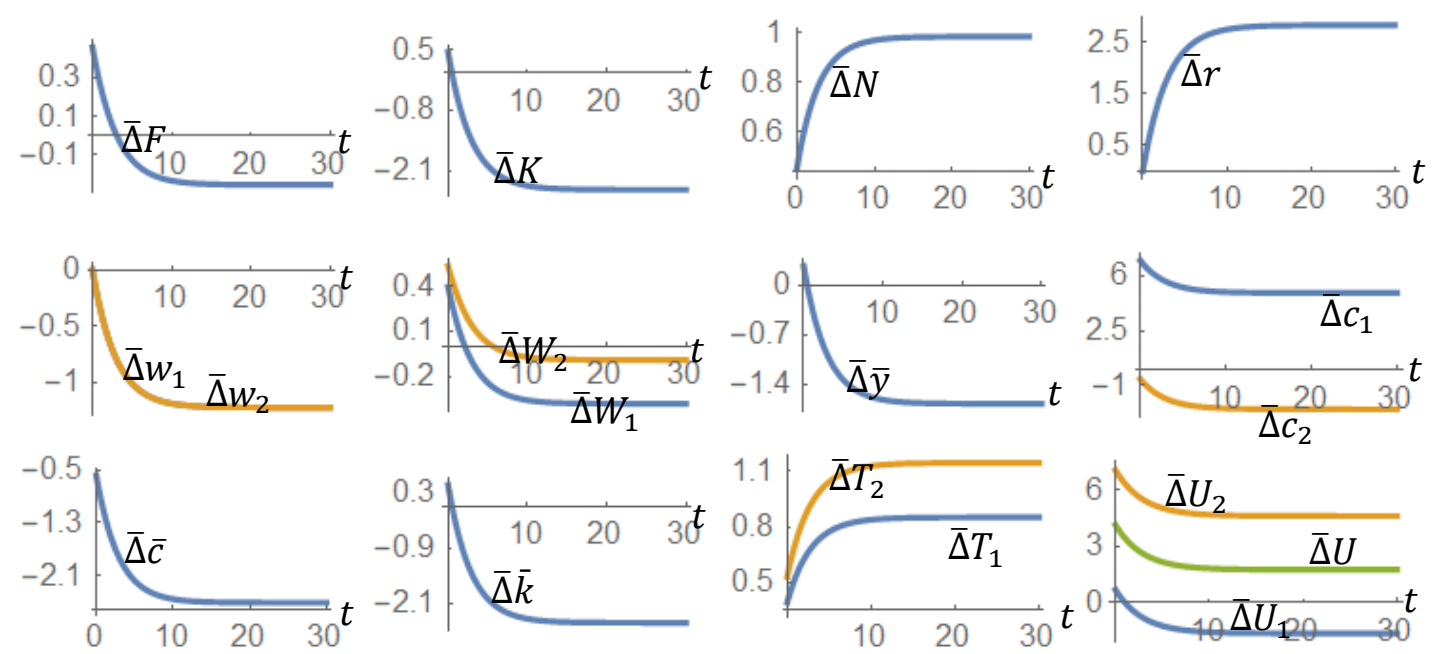

Figure 4. The Wife Cares More about Her Husband 


\section{The wife increases her propensity to save}

We study how the economy is changed if the wife increases her propensity to save in the following way: $\lambda_{20}: 0.62 \Rightarrow 0.63$. Figure 5 provides the simulation result. As the wife tends to save more from the potential disposable income, the family's wealth is augmented. The economy has more capital stocks and produces more. The rate of interest is reduced. The labor supply is enhanced initially but is changed slightly in the long term. The husband and wife increase more labor hours. The wage rate is increased. The couple bring more wage incomes. The husband and wife consume less initially but more in the long term. The family has less family goods initially but more in the long term. The couple have higher utility levels.
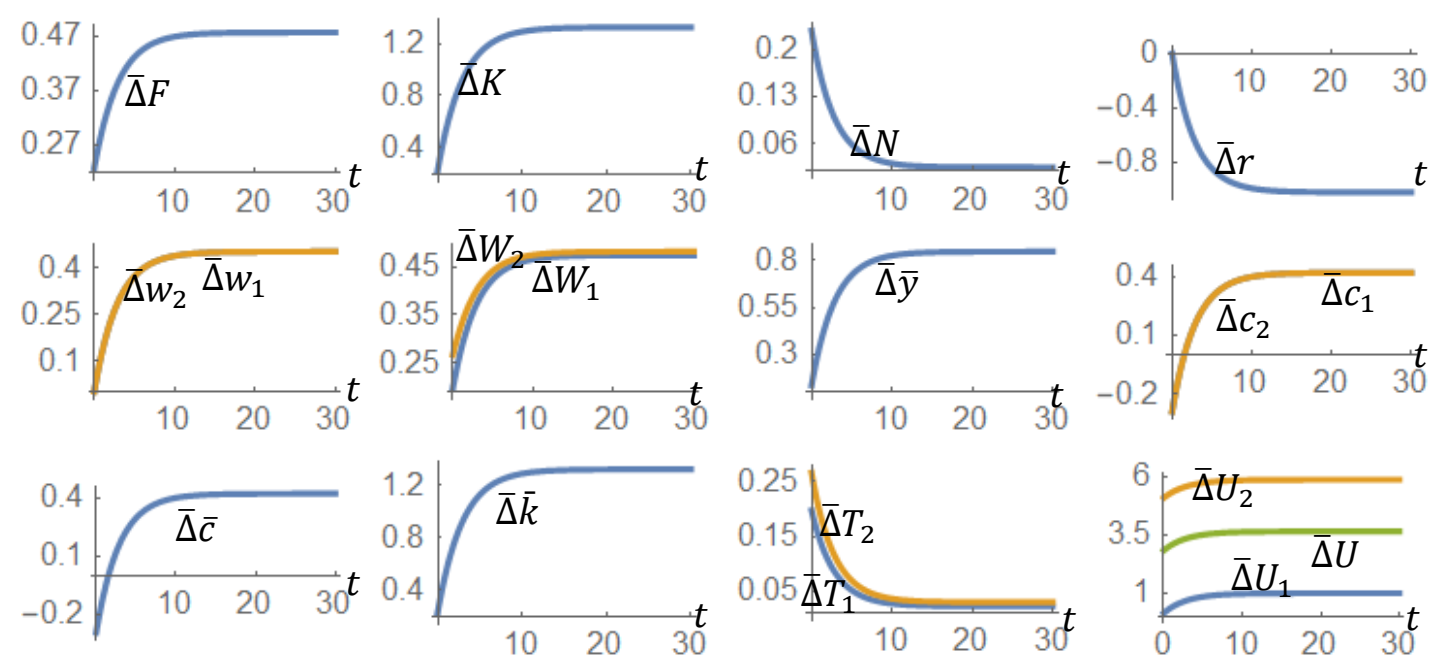

Figure 5. The Wife Increases Her Propensity to Save

\section{The wife increases her propensity to consume goods}

We study how the economy is changed if the wife increases her propensity to consume goods in the following way: $\xi_{20}: 0.15 \Rightarrow 0.16$. Figure 6 provides the simulation result. As the wife tends to consume more from the potential disposable income, her consumption is increased, while her husband's consumption is reduced. The family's wealth is augmented slightly initially but is reduced. The national capital stock and output level are increased initially but reduced in the long term. The rate of interest is augmented. The couple work more hours. The national labor supply is augmented. The wage rates of the couple are reduced. In the long terms the couple bring less wage incomes to the family. The family has less family goods and less wealth. The wife's utility is enhanced, while the husband's utility is reduced. The family utility is enhanced. 

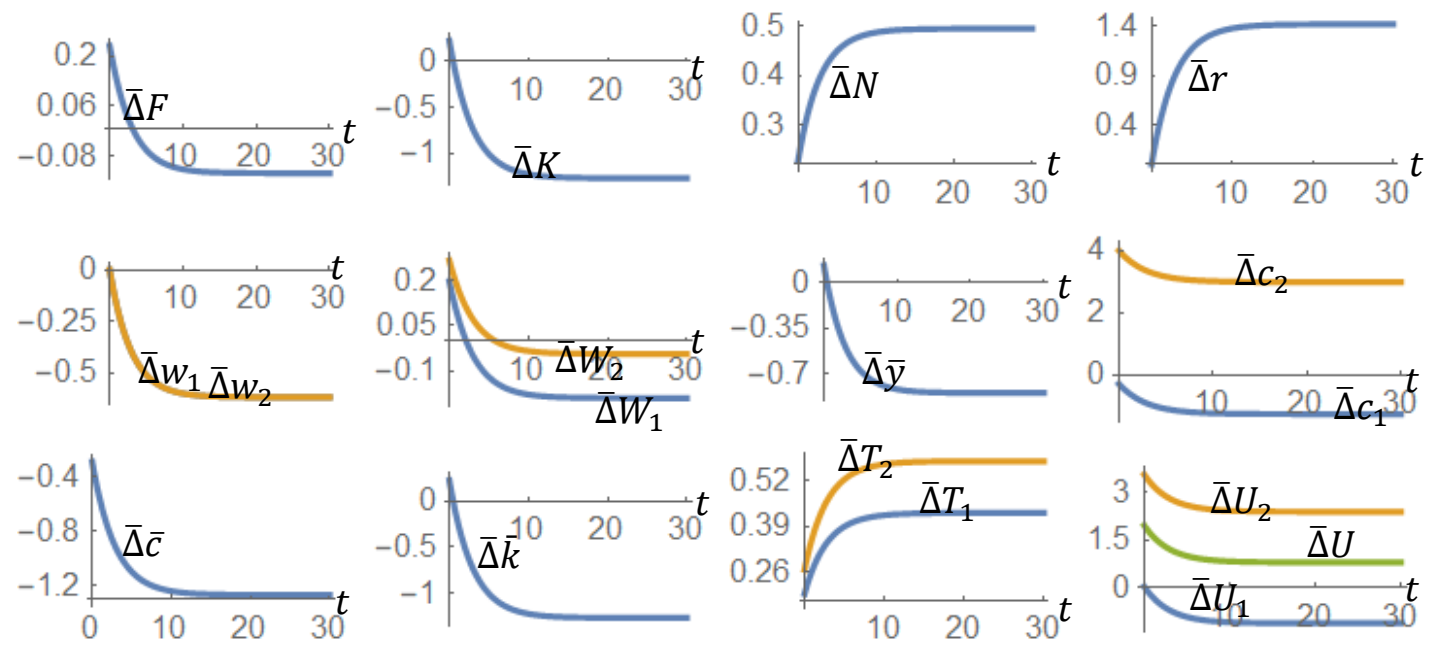

Figure 6. The Wife Increases Her Propensity to Consume Goods

\section{The wife increases her propensity to have family goods}

We study how the economy is changed if the wife increases her propensity to have family goods in the following way: $\gamma_{20}: 0.15 \Rightarrow 0.16$. Figure 7 provides the simulation result. As the wife has a stronger propensity to family goods, the family consumes more family goods. The couple work more hours. The wage rate falls. The couple bring more wage incomes to the family initially but less in the long term. The family has less wealth. The rate of interest is increased. The couple consume less goods. The wife's utility is augmented but the husband's utility is reduced.
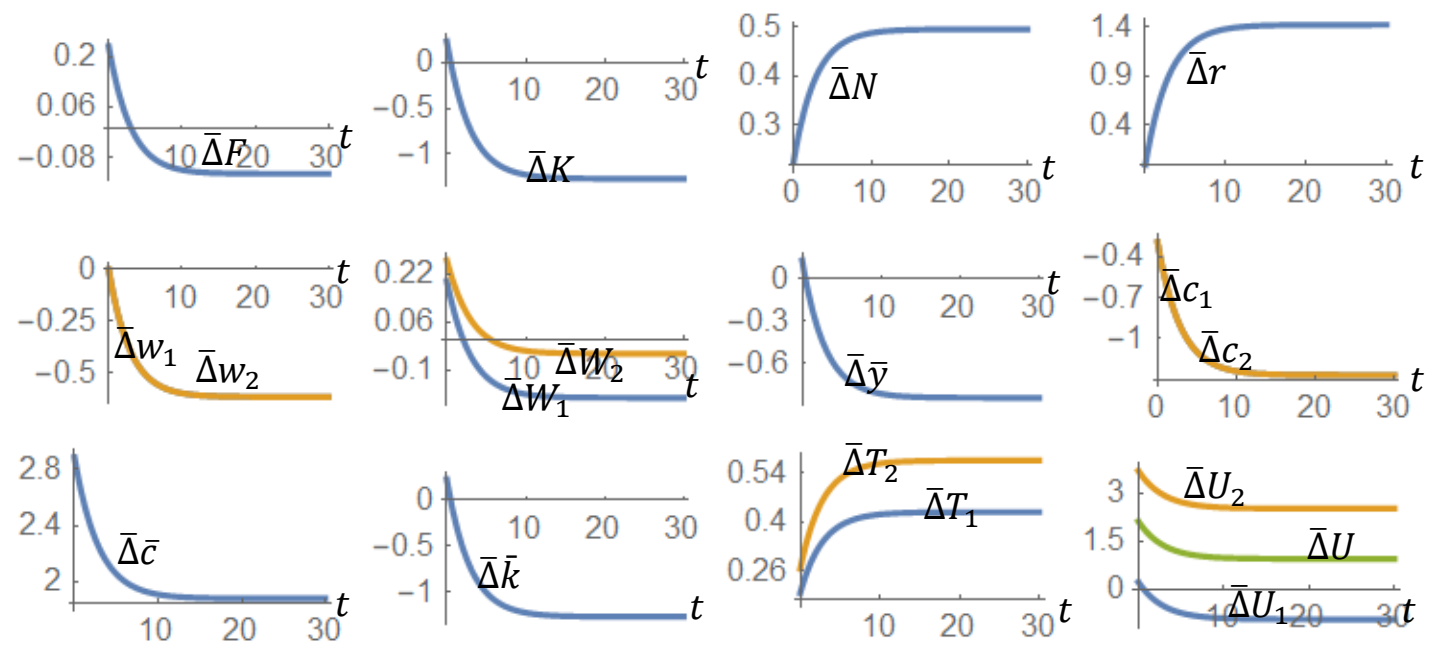

Figure 7. The Wife Increases Her Propensity to Have Family Goods

4.7. The wife increases her propensity to stay at home

We study how the economy is changed if the wife increases her propensity to have family goods in the following way: $\gamma_{20}: 0.15 \Rightarrow 0.16$. Figure 7 provides the simulation result. As the wife has a stronger propensity to family goods, the family consumes more family goods. The couple work more hours. The wage rate falls. The couple bring more wage incomes to the family initially but less in the long term. The family has less wealth. The rate of interest is increased. The couple consume less goods. The wife's utility is augmented but the husband's utility is reduced. 

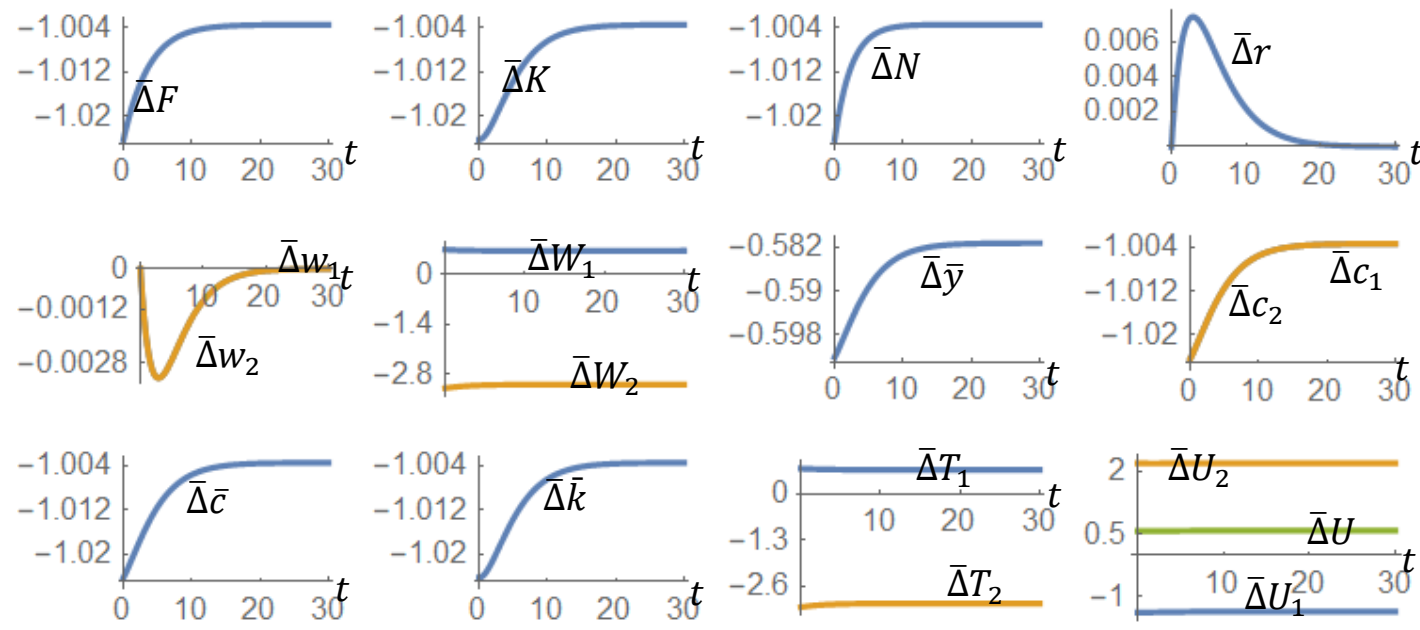

Figure 8. The Wife Increases Her Propensity to Stay at Home

4.8. The total factor productivity is enhanced

We study how the economy is changed if the total factor productivity is enhanced in the following way: A: $1.2 \Rightarrow 1.22$. Figure 9 provides the simulation result. As the productivity is augmented, the national output is increased. The working hours of the couple and labor supply are not affected in the long term. The rate of interest is not affected. The capital stock is enhanced. The consumption levels of the couple are enhanced. The family has more wealth and consumes more family goods. The utility levels are enhanced.
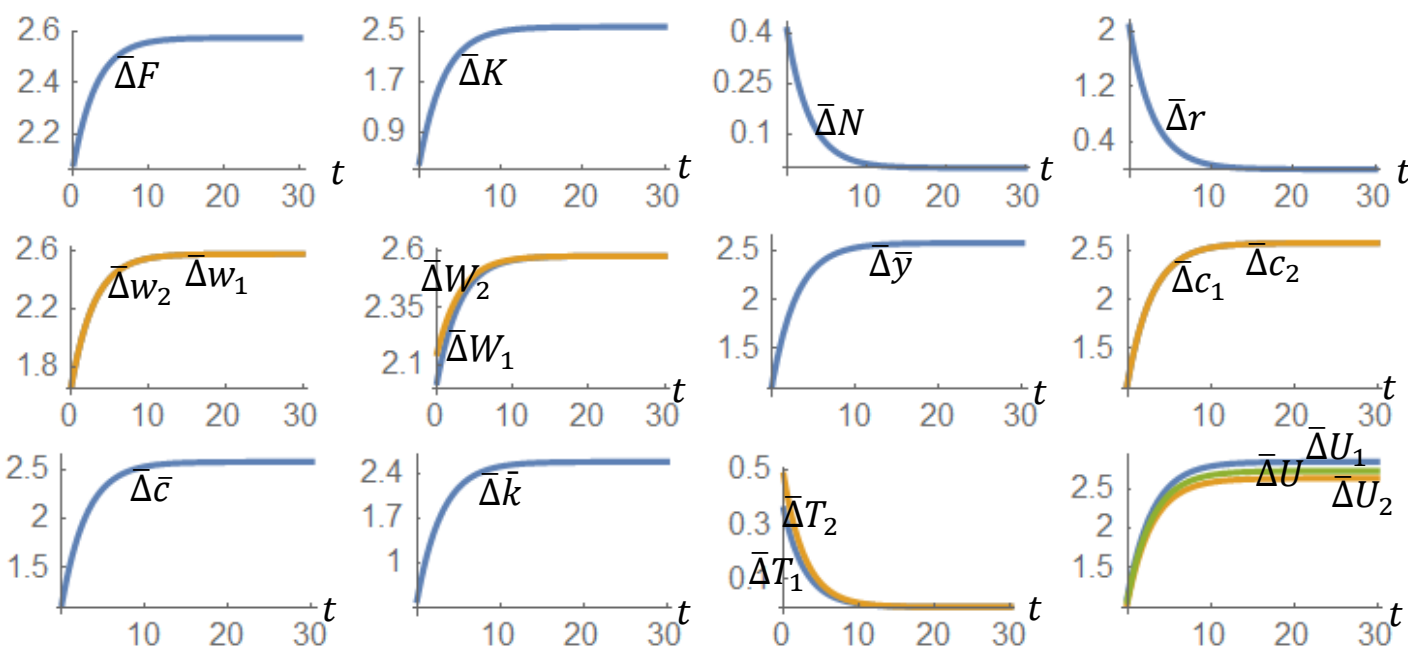

Figure 9. The Total Factor Productivity is Enhanced

\section{Conclusions}

The purpose of this paper is to study economic growth with family-based microeconomic foundation. It develops a neoclassical growth model with homogenous two-person families. Growth mechanism and economic structures are based on a generalized Solowian growth model with Zhang's concept of disposable income and utility. Much of this article was to examine economic growth and family decision making on consumption and saving with given power balance between husband and wife. It may be considered as spadework for further study on 
relations between growth and family behavior. The paper can be extended and generalized in different ways in the light of extensive literature of family economics. Microeconomics has nowadays many comprehensive approaches to various behavior of households. The model can be extended to analyze issues related to, for instance, number of children and population growth. A woman's power might also be limited to certain domain of family decisions. For instance, children' food and cloth might be controlled by the mother (Lundberg and Pollak, 1994). Household's balance of power is a consequence of games between family members. This study considers balance of power as fixed. It is more realistic to consider balance of gender power as a dynamic game (e.g., Basu, 2006). While this feature of household games is well analyzed in the literature of family economics, it has been formally modelled rarely in general framework of economic dynamics with wealth accumulation. The family may actually play an important role in causing institutional changes (e.g., Doepke and Tertilt, 2016). Intergenerational resource transmission is another important issues in family economics (Becker, et al., 2018). In contemporary economies marriage and divorce related to growth, wealth and income distributions, preferences, and education (Chiappori, et al., 2018). We may also take account of heterogeneous households and use more general functional forms of utility.

Appendix: Prove the Lemma

By (14), we have

$$
z \equiv \frac{r+\delta_{k}}{w}=\frac{\bar{\beta} N}{K}
$$

where $\bar{\beta} \equiv \alpha / \beta$. With (A1), (13) and (14), we have

$$
r(z)=\alpha A\left(\frac{z}{\bar{\beta}}\right)^{\beta}-\delta_{k}, w(z)=\beta A\left(\frac{\bar{\beta}}{z}\right)^{\alpha} .
$$

By the definition of $\bar{y}$, we have

$$
\bar{y}(z, \bar{k})=R(z) \bar{k}+T_{0} w_{1}(z)+T_{0} w_{2}(z) .
$$

By (11) and (A3), we have

$$
\bar{T}_{j}=\frac{\sigma_{j}\left(R \bar{k}+T_{0} w_{1}+T_{0} w_{2}\right)}{w_{j}} .
$$

With (4) and (A4)

$$
T_{1}=\left(1-\sigma_{1}\right) T_{0}-\frac{\sigma_{1}\left(R \bar{k}+T_{0} w_{2}\right)}{w_{1}}, T_{2}=\left(1-\sigma_{2}\right) T_{0}-\frac{\sigma_{2}\left(R \bar{k}+T_{0} w_{1}\right)}{w_{2}} .
$$

From (1) and (A4) we have 


$$
N=\sigma-\frac{\left(\sigma_{1}+\sigma_{2}\right) R \bar{N} \bar{k}}{w}
$$

where

$$
\sigma \equiv\left(1-\sigma_{1}-\sigma_{2}\right) h_{1} T_{0} \bar{N}+\left(1-\sigma_{2}-\sigma_{1}\right) h_{2} T_{0} \bar{N}
$$

By (15) and (A1)

$$
z=\frac{\bar{\beta} N}{\bar{k} \bar{N}} \cdot(A 6)
$$

Insert (A5) in (A6)

$$
\bar{k}=\varphi(z) \equiv\left(\frac{z}{\bar{\beta}}+\frac{\left(\sigma_{1}+\sigma_{2}\right) R}{w}\right)^{-1} \frac{\sigma}{\bar{N}}
$$

We see that we can treat $\bar{k}$ as a function of $z$. It is straightforward to show that all the variables can be treated as functions of $z$ as given in the Lemma. We have derivatives of (A7) in time as follows:

$$
\dot{\bar{k}}=\frac{\partial \varphi}{\partial z} \dot{z} .(A 8)
$$

By (12), (A7) and (A8), we have

$$
\dot{\bar{k}}=s(z)-\varphi \cdot(A 9)
$$

From (A8) and (A9), we have:

$$
\dot{z}=\Phi(z) \equiv(s-\varphi)\left(\frac{\partial \varphi}{\partial z}\right)^{-1} \cdot(A 10)
$$

We thus confirmed the Lemma.

\section{References}

[1] Abel, A., Bernanke, B.S., \& Croushore, D. (2007). Macroeconomics. New Jersey: Prentice Hall.

[2] Azariadis, C. (1993). Intertemporal macroeconomics. Oxford: Blackwell.

[3] Basu, K. (2006) Gender and say: A model of household behaviour with endogenously determined balance of power. The Economic Journal, 106(April), 558-80.

[4] Becker, G.S. (1981) A treatise on the family. MA., Cambridge: Harvard University Press.

[5] Becker, G.S. (1988). Family economics and macro behavior. American Economic Review, 78(1), 1-13. 
[6] Becker, G. S., Kominers, S.D., Murphy, K.M., \& Spenkuch, J.L. (2018). A theory of intergenerational mobility. Journal of Political Economy, 126(S1), 7-25.

[7] Ben-David, D. \& Loewy, M.B. (2003). Trade and neoclassical growth model. Journal of Economic Integration, 18(1), 1-16.

[8] Bergstrom, T.C. (1996). Economics in a family way. Journal of Economic Literature, XXXIV(December), 1903-34.

[9] Blundell, R., Dias, M.C., \& Shaw, C.M.J. (2016). Female labor supply, human capital and welfare reform. Econometrica, 84(5), 1705-1753.

[10] Bourguignon, F. \& Chiappori, P.A. (1992). Collective models of household behavior: An introduction. European Economic Review, 36(2-3), 355-364.

[11] Burmeister, E. \& Dobell, A.R. (1970). Mathematical theories of economic growth. London: Collier Macmillan Publishers.

[12] Campbell, J.Y. \& Ludvigson, S. (2001). Elasticities of substitution in real business cycle models with home production. Journal of Money, Credit and Bankings, 33(4), 847-875.

[13] Chen, Z.Q. \& Woolley, F. (2001). A Cournot-Nash model of family decision making. The Economic Journal, 111 (October), 722-748.

[14] Chiappori, P.A. (1992). Introducing household production in collective models of labor supply. Journal of Political Economy, 105(1), 191-209.

[15] Chiappori, P.A., Dias, M.C., \& Meghir, C. (2018). The marriage market, labor supply, and education choice. Journal of Political Economy, 126(S1), 26-72.

[16] Doepke, M. \& Tertilt, M. (2016). Families in macroeconomics, Chapter 23. In J.B. Taylor \& H. Uhlig (Eds.), Handbook of macroeconomics (Vol. 2B, pp. 1789-891). Amsterdam: Elsevier B.V.

[17] Jensen, B.S. and Larsen, M.E. (2005). General equilibrium dynamics of multi-sector growth models. Journal of Economics, 85(S1), 17-56.

[18] Lundberg, S. and Pollak, R. (1994). Noncooperative bargaining models of marriage. American Economic Review, 84(2), 132-137.

[19] Miles, D. \& Scott, A. (2005). Macroeconomics - Understanding the wealth of nations. Chichester: John Wiley \& Sons, Ltd.

[20] Rosenzweig, M.R. \& Stark, O. (1997). Handbook of population and family economics. Amsterdam: North Holland.

[21] Samuelson, P. (1956). Social indifference curves. Quarterly Journal of Economics, $70(1), 1-22$.

[22] Solow, R. (1956). A contribution to the theory of growth. Quarterly Journal of Economics, 70(1), 65-94.

[23] Uzawa, H. (1961). On a two-sector model of economic growth. Review of Economic Studies, 29(1), 47-70.

[24] Vendrik, M.C.M. (2003). Dynamics of a household norm in female labour supply. Journal of Economic Dynamics \& Control, 27(5), 823-841.

[25] Zhang, W.B. (1993). Woman's labor participation and economic growth - Creativity, knowledge utilization and family preference. Economics Letters, 42(1), 105-110.

[26] Zhang, W.B. (2005). Economic growth theory. London: Ashgate.

[27] Zhang, W.B. (2012). Economic growth with heterogeneous households, gender division of labor, and elastic labor supply. Journal of Income Distribution, 21(2), 15-37.

[28] Zhang, W.B. (2016). Population growth and preference change in a generalized solow growth model with gender time distributions. Oradea Journal of Business and Economics, 1(2), 7-30. 